\title{
On the preparation of specimens for scanning electron microscopy and a simple technique for plate making, using a black background
}

\author{
J.E. WHITTAKER \& R.L. HODGKINSON Department of Palaeontology, \\ The Natural History Museum [BMNH], London SW7 5BD
}

\begin{abstract}
Methods for cleaning, the mounting of micropalaeontological specimens (foraminifera, ostracods and conodonts) on SEM stubs and for successful plate making on a black background are described.
\end{abstract}

\section{INTRODUCTION}

Today, the use of SEM photography in taxonomic publication is usually a prerequisite. Yet many authors fail to get the best out of the medium by having dirty specimens or inadequate stub mounting techniques. The published plate of micrographs could also be much improved if a little care was taken in its assembly. More and more journals are rejecting papers because, although the text may be acceptable, the illustrations are not up to standard.

By cutting out the pictures, rather than mounting a series of squares, many more specimens can be mounted on a plate and more than one view of the same object can be mounted side by side. Most people who work on microfossils, prefer to see their photographs mounted on a black background. If it is done well the aesthetic appearance alone is most satisfactory. A good printer can only reproduce what he receives. The following has been prepared as an expanded Instruction for Authors, which, it is hoped, will be of benefit to authors preparing papers for the Journal of Micropalaeontology, as well as for other palaeontological publications.

\section{SEM PREPARATION}

If processing methods are successfully carried out fossil specimens will be clean and need no further treatment before photography, apart from wiping away the odd fragment with a wetted, fine Camel hair brush. Similar remarks also apply to Recent material. Where further cleaning is required this can be done by soaking in water. In some cases a small amount of proprietory cleaning agent such as 'Decon' or 'Extran' can be added during the soak, to remove stubborn dirt, but care must be taken not to damage the surface of the specimen since it has been shown (Hodgkinson, in preparation) that during prolonged contact, etching can take place. Final cleaning can be done by placing the specimen on a slide and wiping with a wetted brush or temporarily glueing the object down and prodding with a needle or stiffened paint brush to remove the remaining dirt or last stubborn fragments of sediment. There is no excuse for dirty specimens!

The specimens can be fixed to stubs for SEM photography by several means: they can be glued to a glass coverslip previously stuck to a stub by 'Loctite' (or 'Lakeside 70C cement' or other heat-proof adhesive), with a water-soluble glue such as 'Cellofas' (carboxy methyl cellulose) or with 'Gum tragacanth'. Another method is to glue a square piece of exposed negative film, emulsion side up, to the stub with 'Loctite', and the specimens are then fixed to it with a little moisture; the gelatin of the film surface affords the necessary 'hold' once wetted. For larger specimens of foraminifera and ostracods (over $600 \mu \mathrm{m}$ diameter/length) 'Lakeside' cement diluted with acetone can be used, or an extra drop of watersoluble glue can be placed under the specimen, to avoid the danger of its becoming unattached from the film.

Be careful with glues, even water-soluble ones, and use a separate brush for the glue, to the one used to position the specimen. If negative film is used there is no danger of getting glue on the specimen, but 'wisps' of gelatin can become attached and should be looked out for. 'Double sided tape' ('Sellotape' or the like) is not recommended as specimens can sink into it and the heat from the SEM beam causes crazing of the background; furthermore, it is responsible for contamination of the SEM column. In our experience, the best natural background can be got from 'negative film' if kept clean. Another excellent background is provide by 'metal tape' stuck to a stub, but difficulties have been experienced in getting specimens to stick to it. The ease of mounting procedure on 'negative film' also enables the same specimen to be remounted more than once, for different views, and subsequent micrographs are not disfigured, as often is the case when glues are involved. The only problem in mounting we have experienced was in obtaining good pictures of apertural slits in such genera as Bolivina and Uvigerina (foraminifera). By making a small hole in the film with a needle and by placing the sharp initial end in it and wetting, it was found relatively easy to get the specimen to stand up while at the same time leaving it securely attached to the stub. Alternatively, modern scanning electron microscopes with a high tilt capability (up to $90^{\circ}$ ) can enable the operator to photograph different views of the same specimen, including apertural shots, without the need for remounting.

Charging used to be a problem in SEM photography but the advent of the 'sputter coater' has changed this overnight. The methods for removal of coatings (gold, gold-palladium, aluminium and carbon) are briefly mentioned by Golden (1989). 
We find that cyaniding (Hansen, 1968), for the removal of gold, does not appear to visibly harm the majority of specimens treated, but more experimental work on a variety of microfossils is needed before pronouncing any of these methods completely safe for type specimens. The necessity of coating important specimens has largely been removed by the use of an Environmental Chamber attached to a standard SEM, in conjunction with a backscattered electron detector (Taylor, 1986). All that is required is that the specimens be clean and dry. Fragile specimens can be left on their slides, provided much of the moisture (if the slide is cardboard) has been removed by an overnight stay in a dessicator; only the cover slip needs to be removed.

We are unable to suggest a foolproof way of preserving very small and fragile specimens on SEM stubs. The researches of Witcomb (1981 \& 1985) on the problems of mounting media are extensive and informative and should be noted. Poor adhesion (on wax or double-sided tape) may eventually cause the loss of many valuable specimens and it is the duty of the preparator, to save the curator this embarrassment by removing specimens from their stub, if at all feasible, prior to presentation to a museum.

\section{PLATE MAKING}

The Natural History Museum prefers to use 120-size negatives. This is because the quality of the final image in enlargements and in projection slides is far better than from $35 \mathrm{~mm}$ film. On receiving the prints, first carefully blacken around the edge of each image with a felt-tip, or fibre-tip pen and then cut out with a fine pair of scissors to within a few millimetres of the edge of the specimen. The finished result is much neater than with images cut out flush. The cut edge of the photograph must be carefully blackened with a thicker felt pen otherwise it will show as a white line in the final plate reproduction. The photographs are stuck to a black background with a rubber solution, such as 'Cow Gum', so that their removal is always possible later, furthermore it does not leave smears on the background as do many other proprietory glues, thus spoiling the appearance of the plate. Stick the photographs down, placing a sheet of tracing paper or grease-proof paper over the plate before pressing under some heavy books for several hours. After removing this weight and sheet of tracing paper, allow the excess 'Cow Gum' to dry for 30 minutes and then remove the excess with a cloth or paper tissue. Using a felt-tip pen, this time at an angle, go around each image again to ensure all traces of the white edge of the photograph are eliminated. After several experiments, the best black background was achieved by dry mounting exposed and fixed, glossy (not matt) black photographic paper onto white card (to give extra strength). If, however, the printer is to produce half-tones using the laser scanning technique, then a flexible plate, either an original or a good photographic reproduction, is desirable as the plate has to be mounted on a cylinder. Check with the journal editor, if unsure. We make up plates at least twice the final size and these are then reduced photographically, usually by the printer. This reduced blemishes such as the 'white line effect' and with a 120 -size original negative, if one is to mount many photographs on a plate, a large-size original plate is essential if one is not to end up having to produce prints of a smaller initial size than the negative. This would not be a problem with $35 \mathrm{~mm}$ film and a plate to the same size as the journal page can be more readily achieved.

This plate making procedure is simple, when compared to the complex masking process described by Bengtson (1986), and failsafe and produces an aesthetically pleasing plate on a perfect black, clean background. There is also no need for the printer to have to mask the plate, which is expensive. The background is also very black on printing, unlike plates made up on black cardboard which invariably come out grey. Some plates published in the Journal of Micropalaeontology using this method include Athersuch et al. (1983), Bevan (1986), Jenkins et al. (1986) and Haynes \& Whittaker (1990).

\section{ACKNOWLEDGEMENTS}

The authors are indebted to Mr D. Claugher (formerly of the BMNH), also Drs J. Athersuch (PB Sunbury) and D.J. Horne (Thames Polytechnic) for their contributions to the evolution of the successful methods described herein.

Manuscript received February 1990. Manuscript accepted August 1990.

\section{REFERENCES}

Athersuch, J., Horne, D.J. \& Whittaker, J.E. 1983. Some species of the ostracod genus Bythocythere Sars from British waters.

J. micropalaeontol., 2, 71-81, pls 1,2.

Bengtson, S. 1986. Preparing clean backgrounds in published photographic illustration. Lethaia, 19, 361-362, Fig. 1.

Bevan, J.C. 1986. The electron microprobe analysis of agglutinating foraminifera; results from a Rotaliammina test from the S.W. Pacific. J. micropalaeontol., 5 (1), 77-81, pl. 1.

Golden, J. 1989. Golden oldies: Curating SEM specimens. Coll. Forum, 5, 17-26.

Hansen, H.J. 1968. A technique for removing gold from plated calcareous microfossils. Micropalaeontology, 14, 499-500.

Haynes, J.R. \& Whittaker, J.E. 1990. The status of Rotalia Lamarck and of the Rotaliidae Eherenberg. J. micropalaeontol, 9: 95-106, pls 1-3, Figs 1-3.

Jenkins, D.G., Whittaker, J.E. \& Carlton, R. 1986. On the age and correlation of the St Erth Beds, S.W. England, based on planktonic foraminifera. J. micropalaeontol., 5 (2), 93-105, pls 1,2.

Taylor,P.D. 1986. Scanning electron microscopy of uncoated fossils. Palaeontology, 29, 685-690.

Witcomb, M.J. 1981. The suitability of various adhesives as mounting media for scanning electron microscopy. 1: Epoxies, sprays and tapes. J. microsc., 121, 289-308.

Witcomb, M.J. 1985. The suitability of various adhesives as mounting media for scanning electron microscopy. 2: General purpose glues. J. microsc., 139, 75-114. 